\title{
Is biodiversity aging? Heuristic questions on the taxonomic diversity in the Phanerozoic
}

\author{
Longino Contoli Amante
}

Via Arno 38, 00198 Roma, Italy

ABSTRACT

KEY WORDS

The trend of numerosity component of diversity was analysed from palaeontological data, according to various time intervals and taxonomical ranks. Taxa numerosity of lower (with respect to family), with a nearly exponential increase, vs. higher ranks (from order to macrotaxon), with mainly a logarithmic trend, confirms to follow quite different patterns over time. This dataset seems to fit with a more assortative hypothesis, for higher taxa and a more divisive one for lower taxa. Then, a model was built to quantify the relative weight, over time, of the above hypothetical evolutionary components of various taxa ranks; such ranks were identified, in a palaeontological approach, by the maximum number of recorded taxa or, in a phyletic approach, by the time duration based on genetic data. The trends obtained by this model agree with observed records and the hypothesis, to be verified, of a quite different evolutionary origin of macro- (phylum, class, order ranks) and micro-taxa (genus and species), during the transition between two main time phases: the first (evidently more assortative), mainly linked to the lateral sharing of characters, the second (evidently more divisive), mainly influenced by the ever growing morpho-physio-genetic isolation even for the protection of complex adaptations, as in the present, "modern species".

Evolutionary models; genetic timing; macroevolution; taxonomic diversity

Received 02.05.2018; accepted 12.06.2018; printed 30.06.2018; published online 05.07.2018

"Iamque adeo fracta est aetas effetaque tellus vix animalia parva creat quae cuncta creavit saecla ..." (Lucretius).

\section{INTRODUCTION}

Since evolutionary theory was accepted as the only possible rational explanation of the life diversification in the biosphere - e.g., Gould (2002); see also Mayr (1982), evolutionary processes have received many and different interpretations. Two main question points have been particularly investigated: (i) the basis of the biological variability, and (ii) the factors orienting its evolution: see, e. g.,
Gould (2002). Moreover, genetics has provided experimental evidence of the "transition" from a species into another species, within a framework that has been defined "microevolution".

However, there has been a contextual difficulty in explaining the great differences in morpho-physiological models, occurring among high-rank taxa like phyla, classes, and orders by means of merely micro-evolutionary processes (Stanley, 1979).

Therefore, Stanley (1979) hypothesized a "decoupling" of selective ranks, between microevolution (selection among individuals) and macroevolution (species as individual units of selection, in macro-evolution, in analogy with specimens in micro-evolution). 
Hence, in order to explain the sudden appearance of organization plans totally innovative, evolutionary biologists invoked mechanisms - see Gould (2002) for an extensive synthesis, that include exaptation, polyploidization, neoteny, lateral transmission, and the passages from individual to colony (or society) to super-individual, related to patterns of complexification of genic complexes, up to the confluence of morphophysiological characters of different taxa in a single one through, e. g., endosymbiosis, parasitism, trophism, hybridization even between well distinct groups, up to the confluence of various taxa into a single biological cycle (Landman, 1991; Doolittle, 1998, 2000; Goldenfeld \& Woese, 2007; Gould et al., 2008; Sanchez-Puerta \& Delwiche, 2008; Archibald, 2009; Dagan \& Martin, 2009; Kleine et al., 2009; Rogozin et al., 2009; Liu, 2011); see also Williamson (2003); recently, Oakley (2017), with a formal and general approach.

It remains, however, to be discussed whether the complexification of the above-mentioned mechanisms is just a sub-group of the whole complexification, which includes also the dimensional increment, coloniality, sociality, and even the indirect development (with or without metamorphosis).

In addition, it has been observed that the genetic roots of micro- and macro-evolutionary aspects may be surprisingly coincident (Gompel et al., 2005).

According to a classical view: e.g., Rensch (1959), the emerging of new, increasingly differentiated taxa into the history of the life on earth, should have been gradual in time (i.e. from species to genus, from genus to family, from family to order, etc). However, since the Palaeozoic, there has been a tumultuous appearance of the majority of the greater taxa, whereas in more recent times there has been a huge increment in the appearance of the number of minor taxa such as species and genera (Signor, 1978, 1982, 1985; Raup, 1983; Benton, 1993, 2001; Smith, 2001; Sepkoski, 2002; Lane \& Benton, 2003; Bush \& Bambach, 2004; Jackson \& Johnson, 2001; Holland \& Sclafani, 2015; but see, e.g., Mc Gowan \& Smith, 2008; Ruban, 2010). Nearly all these minor taxa can, however, be inserted into already-known greater taxa (orders, classes, and phyla).

The family rank, appears to be intermediate and pivotal even in relation to the previous topic and the relevant trend (Sepkoski, 1979; Benton, 2001; Benton \& Emerson, 2007) appears as intermediate be- tween that of orders and genera, perhaps due also to the variety of taxonomic approaches.

There was also a great difference among the various models proposed to interpret the patterns of taxonomic diversity in the Phanerozoic (see, e.g., Valentine, 1970; Valentine \& Moores, 1970; Schopf, 1979; Wise \& Schopf, 1981; etc.). This great difference can be interpreted as a possible influence of the taxonomic rank chosen by the different authors (Lane \& Benton, 2003; Markov \& Korotaiev, 2007), i.e. a low rank (species-genus) (Raup, 1976a, b; Bambach, 1977; Valentine et al., 1978) or at high-rank (order etc.) (Gould et al., 1977; Sepkoski, 1978). Indeed, also the "consensus" model (Sepkoski, 1978) showed that there was a high numerosity of higher taxa in the most ancient phase of the history of life, and a higher numerosity of the lower taxa in the most recent phases. In particular, both the low taxa numerosity during the early phases of the history of life, and the Cenozoic explosion of low-rank taxa, cannot be attributed to artefacts (Signor, 1978, 1982, 1985). Anyway, Benton \& Emerson (2007) did not consider that it is possible to identify a single model explaining the whole variety of contexts and taxonomic ranks. Important new discoveries (such as for the "evodevo") have strongly challenged and re-evaluated old certainties (Gould et al., 1977; Gould, 1989, 2002). For instance, on the homologies and analogies of characters, the prevalent stability of evolution over time with relatively strong accelerations through cladogenesis, hierarchic selection models (from gene to species and beyond), evolution by reductive instead of addictive diversification of the gene complexes, and historical evolution of a same aptitude-to-evolve and the role of the complexity science in the evolutionism (Kauffman, 1993).

This fact has carried to important intuitions, although these intuitions have not been always demonstrated: e.g., the structural approach to the form-function relationship (i.e., exaptation) or a distinct "historic" determinism of the macroevolution, partly differing from that of microevolution (Gould, 2002).

So, it has also been proposed to place, together with the classical view of an adaptive evolution through qualitative mutations, also an evolution through progressive complexification due to the increasing of the hereditary pool (Ohno, 1970; Bateson, 1979; Taylor, 1979; Omodeo, 1985, 2010). In 
the present paper, the expression "assortative evolution" was preferred, as evolutionary complexification linked to the confluence of distinct and different taxonomic sources.

Palaeontology is ever fundamental to understand the distribution and evolution of biological taxa during the history of the Earth and to define the time intervals characterizing the main phases of evolution. Today, such studies are positively supported by neontological advances, e. g., of genetics and its molecular bases. In any case, there is now a wide consensus, e.g., in determining as the beginning of the Phanerozoic the formation of a "modern" atmosphere, conditioned by $\mathrm{O} 2$, around 600 Ma (Farquhar, 2009; Omodeo, 2010; Karhu, 2012). Possibly, in time, the biosphere, which was nearly virtual in the early phases, assumed a real volume becoming with time more and more influenced, even in its abiotic components, by living organisms which were increasingly conditioned in their morphological evolution by bio-coenotic interactions and the relative adaptive responses (Butterfield, 2007).

Hence, if the early interactions occurred mainly with the abiotic environment (i.e. they could be fundamentally biochemical interactions), the successive interactions were mainly done with the biotic environment, through ecological niche processes such as competition, predation, and mediating characteristics such as vagility, modularity, body size increases, etc. Hence, with the Phanerozoic, it became possible the reliable identification of the greater phyletic groups based on macro-morphology of taxa.

Indeed, until now the determinism of the early phyletic diversification versus the later diversification of the lower taxa remain extremely doubtful.

A suite of analyses was applied to these morphologically identified taxonomic groups, in order to test whether the numerosity pattern over time of the high-rank taxa (phyla, classes, orders; see, e. g., Contoli \& Pignatti (2011) and of the low-rank taxa (genus, species) may have a substantially different causal origin; so perhaps extending the ideas of Woese $(2002 ; 2004)$ up to the last part of the preCambrian.

In particular, it has been verified:

whether and how much the trends of numerosity of more or less inclusive taxonomic ranks (e. g.: orders v.s genera) differ from each other over time; what are the implications, about these trends, of the theoretical assortative or divisive outlines;

if these patterns prevail in the outlines observed in real taxonomic ranks;

the predictivity of a model based only on the above mentioned theoretical outlines, in relation to the relative numerosity of taxonomic ranks according to the fossil record.

\section{MATERIAL AND METHODS}

\section{Sources of data}

To analyze the curve fitting of observed numerosity of orders and genera over time, the data reported have been used, even in a graphic way, by Benton (2001).

The macrotaxa (see above in the text) and orders were considered "large taxa", "small taxa" the genera and species. If one compares between them a rank of a small taxa with one of the large taxa without emphasizing most of the differences, among the possible comparisons in the hierarchical succession of ranks, orders and genera are the least distant and, therefore, their comparison is the most prudent.

\section{Chronology}

To evaluate the temporal patterns of the record, considering also the observations of Benson \& Mannion (2011) and Lloyd (2011), the time values of the geological periods were not used directly; indeed, in order to estimate the numerosity of taxa, the time of passage from increasing and decreasing trends or vice versa has been used, i. e., the maxima and minima peaks separating following trends.

When it was convenient, the record was subdivided into intervals of 100 million years, utilizing the highest number of taxa observed, independently from conventional boundaries of geological periods, in order to buffer the more or less random environmental fluctuations on which the above boundaries are usually based.

Indeed, considering the maximum values for each period means taking into account the real potential for each period, thus avoiding all those contingences which may have conditioned stochastically the duration and the strength of the observed "minima" or of the "extinction crises". 
For numerosity frequencies relative to families the values suggested by Raup (1976a, b) and followed by Signor (1978, 1982, 1985), Benton (2001), Jackson \& Johnson (2001), Sepkoski (2002), Benton \& Emerson, 2007), Smith (2007) and Contoli \& Pignatti (2011), were compared.

\section{Methodological problems about Taxonomy}

The most complete dataset in terms of both continuity and regularity regards marine animals.

Owing to the obviously very different sampling completeness of neontologic vs. palaeontologic sampling, only the latter data were used, even in case of the Cenozoic.

It is also obvious that the same taxa ranks in different phyla may not be always perfectly equivalent; however, they are equivalent in terms of their relative inclusiveness and morphological differentiation relatively to the other ranks. Even the evolutionary similarity inferred by time duration data based on genetic distance (see Appendix 1 and 2, online) shows that the mean duration of taxa for each taxonomic rank should be different and distinguishable, even if partially overlapping.

So, in the model, instead of the absolute ones, it has been preferred to use frequencies, relatives to that of families, as a pivotal taxonomic rank.

To test, with the model, the hypothesis that the trends over time of different taxonomic ranks depend on their relative numerosity with respect to the intermediate one of the families, values from literature were needed, even if approximate.

Analysing the whole palaeontological record, Sepkoski (2002) seems to suggest that there is oneorder of magnitude difference among the numerosities of successive taxonomic ranks.

Other authors (Jackson \& Johnson, 2001) consider that the ratio between coexisting genera and species should be between 1 to 10 and 1 to 5 .

Benton (2001) inferred a ratio of 1 to 4 between families and genera or of 5 to 1 between families and orders.

Moreover, according to Smith (2007; Fig. 7), the average ratio between species and families is $\approx 64$; so, it was inferred, between genera and families, the average ratio of 8 to $1 \approx \sqrt{ } 64$.

Lastly, the ratio of $\approx 0.034$ between macrotaxa and families is implicitly suggested by Contoli \& Pignatti (2011).
Analogically, between orders and families, it was inferred the average ratio of 1 to $5 \approx \sqrt{ } 0.034$.

Therefore, according to the above mentioned Authors, the minimum and maximum frequencies, related to families, were, for macrotaxa, respectively $\approx 0.01$ and $\approx 0.035$ (rounded up to 0.04 ); for orders $\approx 0.1$ and $\approx 0.2$; for genera $\approx 4$ and $\approx 10$; for species $\approx 20$ and $\approx 100$.

It is clear that, for this last rank, a homogeneous concept of species would be needed, for the study of the origin and end of the same, taking also into account, the appropriate observations of Ezard et al. (2011).

Then, the model was tested with the above 2 series of relative frequencies.

\section{Biodiversity}

To be emphasized, the present work was not looking for a richness analysis, but for a numerosity one, thus not linked to any weighting procedure.

On the other hand, numerosity can be considered, not only as a weighting base (e.g., for richness evaluation; see also Ganis, 1991; Contoli Amante, 2007, Contoli Amante \& Luiselli, 2015), but also in itself, especially if pertaining to the same scale of data source.

In order to make a proper taxonomic numerosity analysis at the biospheric scale, it is necessary to apply an approach not influenced by evenness.

So, the unweighted taxa numerosity data from literature was directly used.

\section{The model}

To propose an explicative model of different trends observed in various taxa ranks, it was needed to parameterize their characters. Note that, if the biological meaning of the various taxa ranks is strongly subjective, nevertheless the above ranks, by definition, represent a hierarchic series of taxonomic ranks (subdividing the same set of organismic individuals) from the less to the more comprehensive and, so, including, among their individuals, respectively a greater or a lesser "evolutionary similarity".

Obviously, in a given lineage, a taxonomic rank is more comprehensive, while its numerosity is less, i. e. the numerosity of the taxa of the same rank; and vice versa. 
So, for each taxonomic rank, the average evolutionary affinity between the various taxa can be expressed by the numerosity of the given taxonomical rank. Indeed, since the main taxonomic ranks are formally the same, across the whole life in the earth, every taxonomic rank includes and subdivides the whole fossil record and its diversification range; so, if that range is subdivided on more v.s fewer single taxa of a given rank, each of the above, single taxa must be, conversely, fewer v.s more different in its evolution; it results that higher numerosity at a given rank corresponds to higher average evolutionary similarity in a given taxon of the same rank.

The work was interested to compare between taxonomic ranks, not their absolute values; thus, the relative numerosity, with respect to families, of taxa of each rank will be the searched parameter of the modeling analysis.

The model can be applied to any temporal scale starting with the Phanerozoic and ending with the present.

\section{Palaeontology}

The maximum recorded number of taxa pertaining to the " $i$ " rank can help to parametrize the various ranks. Moreover, the taxa numerosity of "i" should be directly proportional to an "evolutionary similarity" within such a taxon rank.

In the hypothesis to be modelled, in a first phase (assortative and logarithmic), the evolutionary divergence was mainly expressed by more comprehensive and, so, less rich taxa ranks; in a following phase (divisive and exponential), by less comprehensive and richer taxa.

In the "taxa in time" model, a logarithmic and an exponential component inversely linked to maximum number of taxa were summed, among the recorded time periods of the Phanerozoic.

By dividing the " $\mathrm{i}$ " numbers of taxa (pertaining to the taxonomic ranks of macrotaxa, orders, families, genera, and species) by that of families, as an intermediate taxonomic rank, it has been obtained:

$\mathrm{N}^{\circ}$ taxa "i" originated at " $\mathrm{t}$ " time $=$ $=\mathrm{k}[\log (\mathrm{t} / \mathrm{t}$ "final" $\mathrm{x}$ taxa "families"/taxa "i $\mathrm{i}$ ") + $+\exp (\mathrm{t} / \mathrm{t}$ "final" $\mathrm{x}$ taxa "i"/taxa "families")].

\section{Genetic data}

Methods were, since long time, conceived and refined, even when with not ever converging results, to evaluate the splitting time among taxa, estimating so also their duration. Altogether, clear differences can be observed among the various taxonomical ranks: in general, the more the duration of a taxonomic rank, the more it was comprehensive.

Their average duration in geological time can be a way to parameterize them and, conversely, to estimate their "evolutionary similarity", for the purpose of this present work, even while being aware of the partial uncertainty of these estimates (cfr. e. g. Warnock et al., 2011; Duchène et al., 2017).

In this perspective, from various sources (Novacek, 1992; Michaux et al., 2001; Dubey \& Shine, 2010; Hedges \& Kumar, 2009; Murphy et al., 2012), it has been inferred time duration of a lot of taxa examined by the above Authors and pertaining to the above 5 ranks; then, an estimation of minimal, maximal, and average duration of each taxonomic rank was obtained.

In order to prevent that the average mean of " $i$ " could be influenced too much by:

- the numbers of richer or poorer taxa;

- the maxima or minima, perhaps mainly subject to errors as outliers, were excluded, from utilized data, the extreme maxima and minima;

- were averaged the minus- and plus-variant data of the same level (i. e., first and last, second and penultimate, third and last-but-two, etc.), up to means regularly invariant in the first significant numbers.

As for palaeontological data, for genetic ones it was obtained:

$\mathrm{N}^{\circ}$ taxa "i" originated at " $\mathrm{t}$ " time $=$

$=\mathrm{k}[\log (\mathrm{t} / \mathrm{t}$ "final" $\mathrm{x}$ duration of taxa "i $\mathrm{i}$ "/duration of "families") +

$+\exp (\mathrm{t} / \mathrm{t}$ "final" $\mathrm{x}$ duration of "families"/duration of taxa "i")].

\section{Relationships between palaeontological and genetic data}

As yet suggested, evolutionary similarity of " $i$ " can be conceived as directly proportional to the maximum taxa numerosity and inversely to its time duration; so, between taxa numerosity and time duration an inverse relation was expected and observed.

\section{Extinction}

From the number of taxa of "i" rank and from 
their durations, considering the extinction inversely proportional to minimum duration reported to the average one, the extinction rate was estimated:

$\mathrm{N}^{\circ}$ taxa "i" extinct at " $\mathrm{t}$ " time $=2 \mathrm{xt} / \mathrm{t}$ "final" time $x$ taxa " $i$ " at " $t$ " time/(minimum duration of "i"/ mean duration of "i").

An algorithm proposed for the model:

$\mathrm{N}^{\circ}$ of "i" taxa present at " $\mathrm{t}$ " time $=\mathrm{N}^{\circ}$ of " $\mathrm{i}$ " taxa originated in " $t$ " time - $\mathrm{N}^{\circ}$ of " $\mathrm{i}$ " taxa extinct in " $\mathrm{t}$ " time.

i. e.,

$\mathrm{N}^{\circ}$ of "i" taxa presents at " $\mathrm{t}$ " time $=$

$=\mathrm{k}\{\log [(\mathrm{t}$ time $/ \mathrm{t}$ "final" time $) /$ mean evolutionary similarity of taxa "i" + 1] + exp (t time/ "final" time $x$ mean evolutionary similarity of " $i$ " taxa) -

$-2 x$ t time/ "final" time $x$ " $i$ " taxa originated at " $t$ " time/(minimum duration of " $\mathrm{i}$ "/mean duration of “i”)]\}.

\section{Fitting of the data}

To fit the data from literature with a suitable polynomial, was searched for functions of the smaller degree compatible with a substantially maximal significance; so, all polynomials of growing degree $(1,2,3 \ldots)$ were calculated and then the $\mathrm{R} 2$ values were regressed vs. the growing degree of the polynomials; when the plateau was attained, the polynomial of the corresponding degree was adopted (see, e. g., Figs. 4, 6).

\section{RESULTS}

\section{Theoretical advantages and disadvantages of assortative phyla versus time and evolution}

Increases in complexity are linked to the evolution, with number of adaptations increasing in relation to increasing physiological functions, body sizes, and lifespan.

Hence, an eventual lateral confluence of genes and their morphophysiological expression of characters through their genic basis may originate a new taxon, but this may be true only if the joining genomes are compatible for some essential preexisting adaptations. In the extreme hypothesis of a single new adaptation to be conserved, there will be a $75 \%$ of useful assortments (i.e., with at least one + for each character) (Table 1), whereas in the case of two adaptations, the vital crosses will be approximately $56 \%$ (Table 2), and so on. For the case of one new character added to a previous set, see figures 1,2 .

So, there should be a logarithmic decrease in the evolutionary prospective of the potential intertaxa hybrids during the evolutionary complexification.

Moreover, the adaptive advantage of a hybrid taxon should depend also on the available niche space, which tends to diminish with time due to the increasing competition strength, thus compensating ad abundantiam the free niche space after catastrophic events. For both reasons, during the evolutionary complexification there must be a reduction of the assortative evolution opportunities.

\section{Recorded numerosity of taxa through time}

The recorded variations in the number of lower taxa (genera) and higher taxa (orders) over time are presented in figures 3,5 .

In general, a trinomial pattern was observed, with two inflexions of importance variable from rank to rank. The two curves were very different: the initial portions of the two curves were signifi-

\begin{tabular}{|l|l|l|l|}
\hline & \multicolumn{2}{|l|}{ TAXON "A" } \\
\hline \multirow{3}{*}{ TAXON "B" } & Vital character & Present & Absent \\
& & & \\
\cline { 2 - 4 } & Present & ++ & +- \\
\cline { 2 - 4 } & Absent & -+ & -- \\
\hline
\end{tabular}

Table 1. Viability of potential assortments of 1 character for each taxon.

\begin{tabular}{|l|l|l|l|l|l|}
\hline & \multicolumn{5}{l|}{ TAXON “A" } \\
\hline \multirow{4}{*}{ TAXON "B" } & Vital char. 1,2 & $1+; 2+$ & $1+; 2-$ & $1-; 2+$ & $1-; 2-$ \\
\cline { 2 - 6 } & $1+; 2+$ & $1++; 2++$ & $1++; 2+-$ & $1+-; 2++$ & $1+-; 2+-$ \\
\cline { 2 - 6 } & $1+; 2-$ & $1++; 2+-$ & $1++; 2--$ & $1+-; 2+-$ & $1+-; 2--$ \\
\cline { 2 - 6 } & $1-; 2+$ & $1+-; 2++$ & $1+-; 2+-$ & $1--; 2++$ & $1--; 2+-$ \\
\cline { 2 - 6 } & $1-; 2-$ & $1+-; 2+-$ & $1+-; 2--$ & $1--; 2+-;$ & $1--; 2--$ \\
\hline
\end{tabular}

Table 2. Viability of potential assortments of 2 characters for each taxon. 


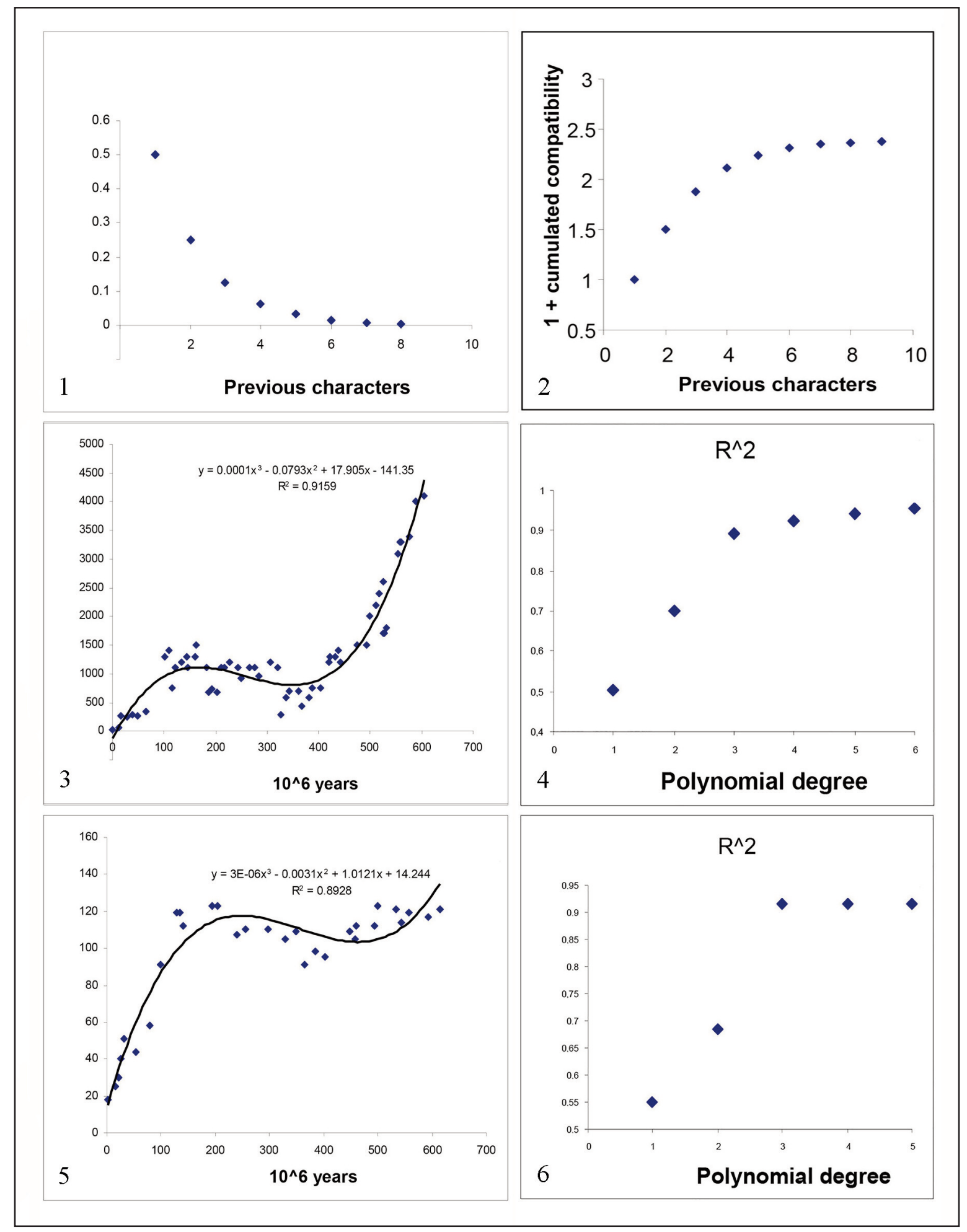

Figure 1. Theoretical compatibility of an added character to a previous set. Figure 2. Compatible assortments of an added character vs. the previous set. Figures 3, 4. Variation in the number of lower taxa (= genera) over time (Fig. 3); the degree of the polynomial corresponds to the flex of the " $\mathrm{P}^{\wedge} /$ degree" curve (Fig. 4). Data reported by Benton (2001). Figures 5, 6. Variation in the number of higher taxa (= orders) over time (Fig. 5); the degree of the polynomial corresponds to the flex of the " $\mathrm{P} \wedge$ /degree" curve (Fig. 6). Data reported by Benton (2001). 
cantly positively correlated ( $\mathrm{P}<0.05$; one-way ANCOVA), whereas there was no correlation as for the final portions of the curves (one-way ANCOVA; P $>0.25$ ).

If the significantly fitted polynomials were to be considered, the derivate is negative in the early phases and positive in the late phases. The first phases tend to prevail in the generation of the higher taxonomic categories, and the late phases in the generation of the lower categories, which tend to hegemonize the taxonomic numerosity with time elapsing.

\section{Does time theoretically explain the passage from micro- to macro-evolution?}

The theoretical relationships between time and number of taxa, for both lower taxa (species) and higher taxa (orders) (see Table 3 for the raw data), in the hypothesis of a constant time interval passing between each hierarchic passage from a given taxonomic category to another, are presented in figures 7,8 . It should be noted that the patterns seems consistent with the real data in the case of species, but not as for the macro-taxa, as this hypothetic latter pattern was even more exponential than that relative to species. Hence, in this case, the time cannot simply explain the observed patterns and, namely, the hypothesis of an "autocatalytic" increase in time of the more comprehensive taxa is untenable.

\section{Modeling analysis}

Genetic data are summarized in Table 4. Available palaeontological (Max n.r of observed taxa) and genetic (Minimum, average, Maximum duration in time) data suggest (Table 5) the relevant values of evolutionary relatedness among taxa of the same rank, relatively to the families.

In both kind of data, the model (Figs. 9-21; P: palaeontology; G: genetics) shows a trend from a more logarithmic pattern (macrotaxa and orders) to an exponential one (genera and species).

Because the model is relativized to families, values and graphs of such taxa express only the time and cannot account for any fluctuation.

The analysis of Correspondence (detrended or not), Principal components, and Clusters (according to Ward, Euclidean Distance and Single Linkage) shows the central position of time and two distinct groups of variables (both from the record and the model), representing, the first the smaller taxa ranks, the second the larger ones, well separated by the first axis representing the very bulk of variance (Figs. 22, 23); the recorded families seem to join better the smaller taxa, near to the recorded genera; nevertheless, the best fit for families (Fig. 24) is with a first degree (straight) function of time, more than a logarithmic (prevailing at first) or an exponential one (prevailing at the end), in agreement with its intermediate and pivotal position among the taxonomic ranks, confirming Hoffman (1985).

\begin{tabular}{|l|l|l|l|l|l|}
\hline TIME & Species & Genera & Families & Orders & Macrotax \\
\hline 1 & 1 & 1 & 1 & 1 & 1 \\
\hline 2 & 2 & 1 & 1 & 1 & 1 \\
\hline 3 & 4 & 2 & 1 & 1 & 1 \\
\hline 4 & 8 & 4 & 2 & 1 & 1 \\
\hline 5 & 16 & 8 & 4 & 2 & 1 \\
\hline 6 & 32 & 16 & 8 & 4 & 2 \\
\hline 7 & 64 & 32 & 16 & 8 & 4 \\
\hline
\end{tabular}

Table 3. Hypothetical hierarchical increases of various taxonomical ranks in time, according to the gradualist hypothesis.

\begin{tabular}{|l|l|l|l|l|l|}
\hline $\begin{array}{l}\text { Duration in } \\
10^{\wedge} 6 \text { years }\end{array}$ & M.txa & Orders & Families & Genera & Species \\
\hline Minimum & $\begin{array}{l}(195) ; 208 ; \\
226 ; 239\end{array}$ & $\begin{array}{l}(32) ; 48 ; 50 ; \\
52\end{array}$ & $\begin{array}{l}(7) ; 10 ; 11 ; \\
13\end{array}$ & $(5) ; 6 ; 7 ; 7$ & $.1,2, .2,2$ \\
\hline Maximum & $(1237) ; 1237 ;$ & $(470) ; 407 ;$ & $(482) ; 308 ;$ & $(113) ; 88 ;$ & $22,16,12$, \\
& $1237 ; 1156$ & $390 ; 379$ & $277 ; 265$ & $88 ; 88$ & 11 \\
\hline $\begin{array}{l}\text { means } \\
(\mathrm{m}+\mathrm{M}) / 2\end{array}$ & {$\left[10^{2}\right] \times[(7) ;$} & $\begin{array}{l}{\left[10^{2}\right] \times[(3) ; 7 ; 7]} \\
2 ; 2 ; 2]\end{array}$ & $\begin{array}{l}{\left[10^{2}\right] \times[(2) ;} \\
1 ; 1 ; 1]\end{array}$ & $\begin{array}{l}{\left[10^{1}\right] \times[(6) ;} \\
5 ; 5 ; 5]\end{array}$ & $(11) ; 8 ; 6 ; 6$ \\
\hline $\begin{array}{l}\text { min/means; } \\
\text { first signif. } \\
\text { Number }\end{array}$ & .3 & .3 & .1 & .1 & .03 \\
\hline
\end{tabular}

Table 4. Genetic duration ( $10^{\wedge} 6$ years $)$.

\begin{tabular}{|c|c|c|c|c|c|}
\hline & Macrotaxa & Orders & Families & Genera & species \\
\hline PALAEONTOLOGICAL & 0.01 to 0.04 & 0.1 to 0.2 & 1 & 4 to 10 & 20 to 100 \\
\hline GENETICAL & 0.1 & 0.5 & 1 & 2 & 17 \\
\hline
\end{tabular}

Table 5. Ratio between number of taxa at a given taxonomic rank and number of taxa at family rank, as estimator of the evolutionary relatedness. 


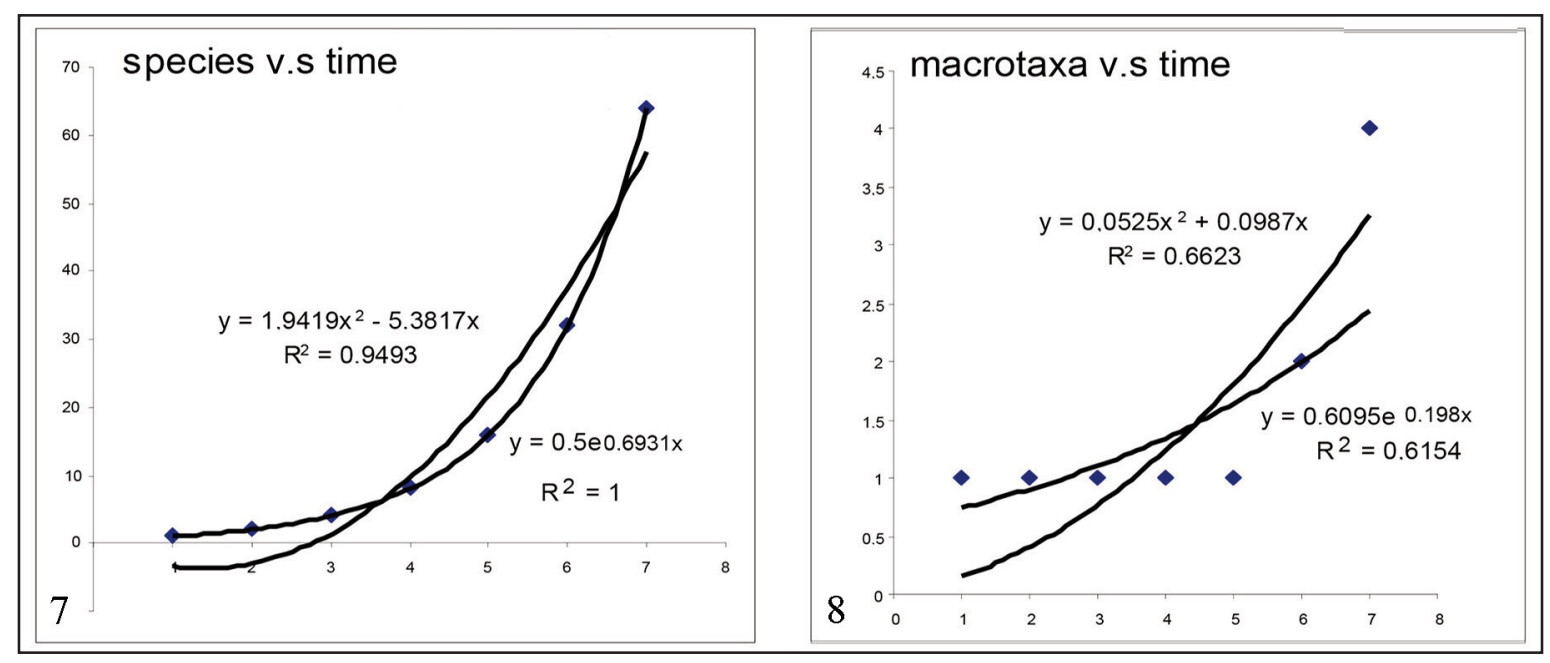

Figures 7, 8. Relationships between time and number of taxa, for both lower taxa (species: A) and higher taxa (macrotaxa: B), in the gradualist hypothesis of a constant time interval passing between each hierarchic passage from a given taxonomic category to another (see Table 3). Fig. 7: species (ordinatae) v.s time (abscyssae). Fig. 8: macrotaxa (ordinatae) v.s time (abscyssae).

Among each of the above two very separated set of variables, the proximity between recorded and model ones of the same rank is less evident, perhaps due to the role of stochastic paleo-geologic events, clearly not affecting the model.

\section{DISCUSSION}

\section{Synthesising the main results}

In general, the patterns about the taxa numerosity which have been highlighted in previous studies (at least since Signor (1985) until Foote (2010) were confirmed, although there were some differences which were mainly due to different authors' perspectives.

The approach developed by Alroy (2008) and Alroy et al. (2010) was not used in the present study. Indeed, although this approach (anyway, still in progress; see Marshall, 2010) is of great relevance for the standardization and comparison of the coenotic data under an ecosystemic key, it may sacrifice a conspicuous part of the available samples that are instead essential for the present study. In addition, the above-mentioned approach obviously enhances the contingent short-term oscillations and depresses the long-term oscillations, that are instead crucial for the scopes of this paper.
In short, the above approach is mainly devoted to richness component of biodiversity, when the present one concern essentially the numerosity.

Hence, the two approaches are not antagonist, but are simply linked to different components of biodiversity and different spatio-temporal scales.

This may partly explain the hyperbolic trend found by Markov \& Korotayev (2007) and Dmitriev (2011). However, the general pattern and the determinism of such aproaches do not contrast with the present analysis. Thus, given the abovementioned approaches, so different in the estimation of changes in palaeontological biodiversity, it was not considered to be appropriate to modify, in a hyperbolic key, the exponential trend deduced, e.g., by Sepkoski $(1967,1979,2002)$ and (Benton, 2001).

Notwithstanding the great methodological differences, the results of the two approaches on the taxonomical diversity in the Phanerozoic (see Sepkoski, 1967, 1979, 2002; Benton, 2001, followed in this work about numerosity) compared to Alroy, (2008), or Foote (2010), concerning richness, are not irreconcilable (see, e.g., Foote, 2010: fig. 18.6) and do mirror in highlighting two distinct growth phases: a first, apparently self-limiting phase, and a second, nearly autocatalytic phase, with a long "crisis" separation. These results are hence in harmony with the findings of this work, highlighting 


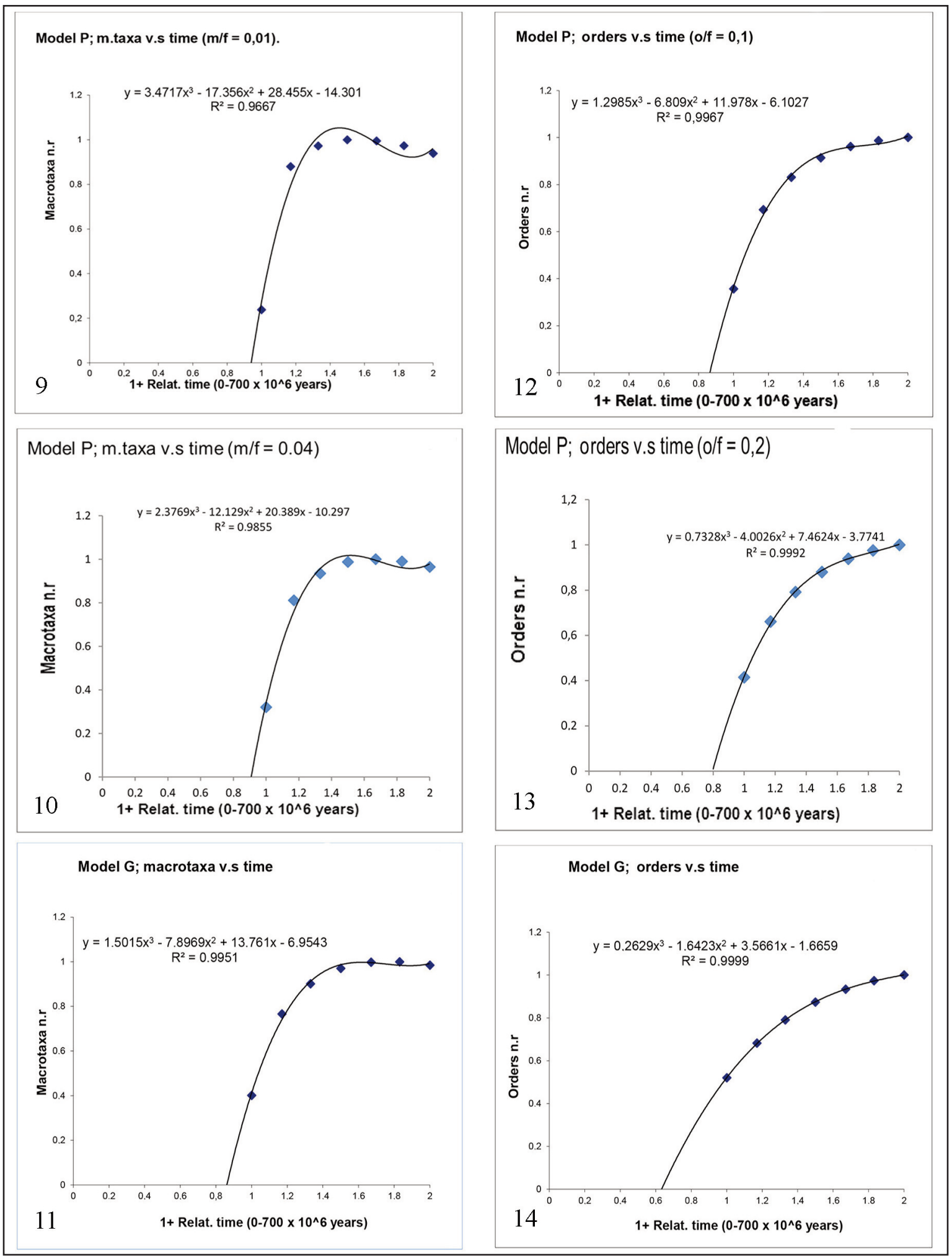

Figures 9-11. Macrotaxa; model P1 (Fig. 9), P2 (palaeontology) (Fig. 10), and G (genetics) (Fig. 11) v.s relative time (0$700 \times 10^{\wedge} 6$ years). $\mathrm{P} ; \mathrm{m} / \mathrm{f}=$ hypothesized numerosity ratio "macrotaxa/families". Figures $12-14$. Orders ; model P1 (Fig. 12), P2 (palaeontology) (Fig. 13) and G (genetics) (Fig. 14) v.s relative time (0-700 x $10^{\wedge} 6$ years). P; o/f = hypothesized numerosity ratio "orders/families". 


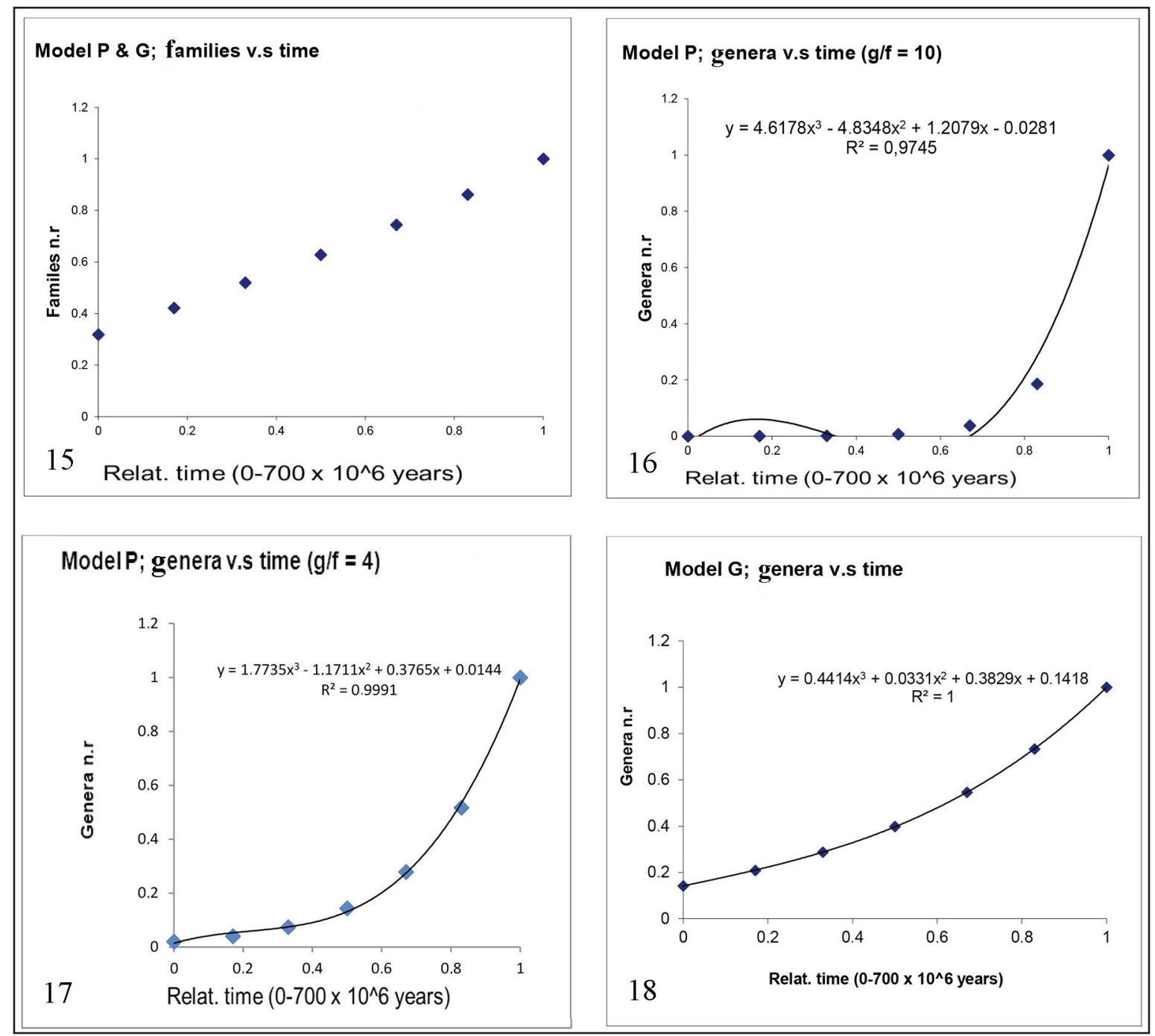

Figure 15. Families; model P (palaeontology) and G (genetics) v.s relative time (0-700 x 10^6 years). Figures $16-18$. Genera; model P1 (Fig. 16), P2 (palaeontology) (Fig. 17) and G (genetics) (Fig. 18) v.s relative time (0-700 x $10^{\wedge} 6$ years). P; g/f = hypothesized numerosity ratio "genera/families".

non-obvious differences between macro- and micro-taxa.

Indeed, with time (i) a mainly logarithmic increment followed by a constancy in the number of macro-taxa (i.e., maintenance of phyla and part of the classes with orders being frequently substituted), and (ii) a nearly exponential growth in the number of micro-taxa were observed.

In the above perspective, the intermediate family rank appears to be a quite heterogeneous and perhaps composite one.

Hence, the present results showed an emerging, and not at all merely formal, difference between macro- and micro-taxa as well as between macroand micro-evolution (Gould, 2002). Indeed, the temporal pattern of the macro-taxa is consistent with a self-limiting model, whereas that for the micro-taxa is typically self-enhancing.

Whilst the micro-taxa patterns (from species to families) are consistent with expectations of the gradualist theory (evolution is essentially a function of time), since at least the Permo-Triassic crisis, the macro-taxa are remarkably different from such expectations, but in agreement with the assortative hypothesis and not in contrast with Gould (2002) and Eldredge (2015). 


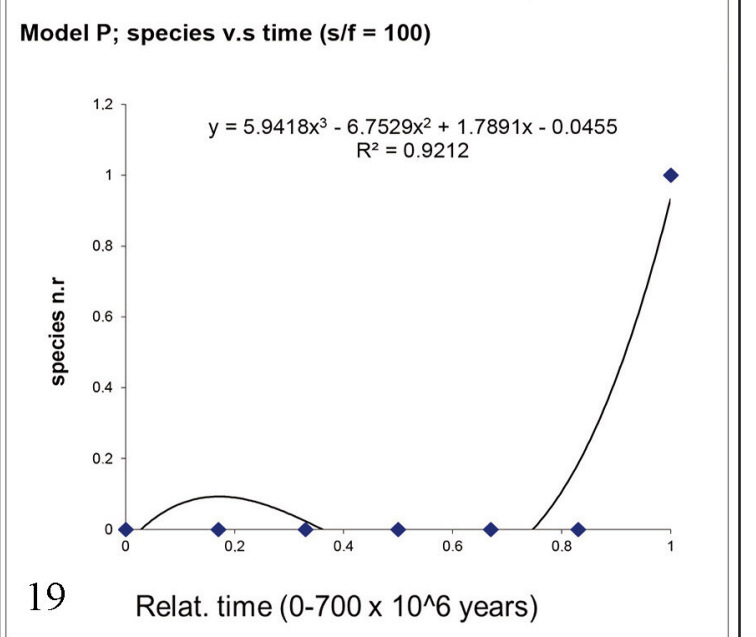

ModelP; species v.s time $(\mathbf{s} / \mathrm{f}=\mathbf{2 0})$

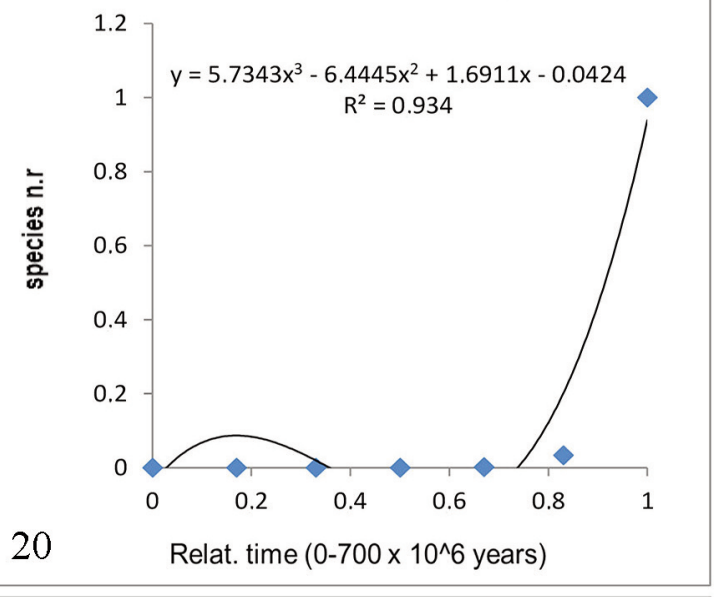

Model G; species v.s time

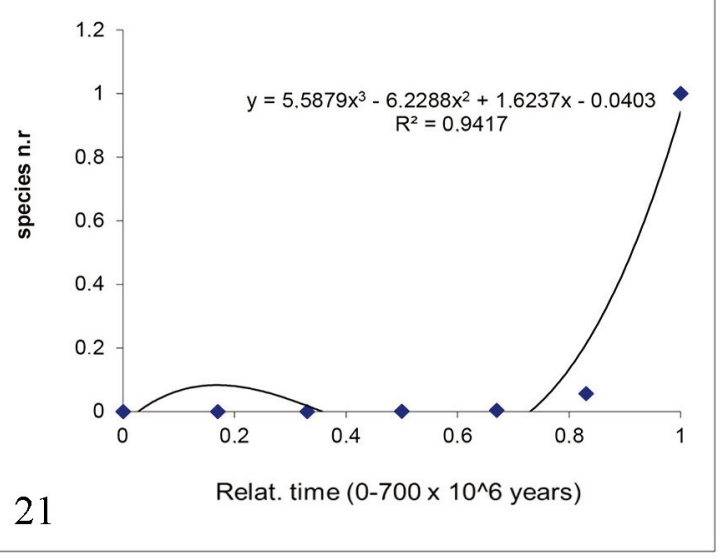

Figures 19-21. Species; model P1 (Fig. 19), P2 (palaeontology) (Fig. 20) and G (genetics) (Fig. 21) v.s relative time $\left(0-700 \times 10^{\wedge} 6\right.$ years $) . P ; \mathrm{s} / \mathrm{f}=$ hypothesized numerosity ratio "species/families".
To finish, it was observed a clear similarity between the theoretical and the observed patterns in time for macro-taxa (Fig. 2 vs. Fig. 5) contrasting with micro-taxa (Fig. 7 vs. Fig. 3), according to two very different hypotheses.

These results encouraged to suggest a quite simple model which, according to the above hypothesis, can unambiguously explain the biological basis of temporal patterns of relative numerosity of both macro- and micro-taxa, considering also the chosen time scale $\left(10^{\wedge} 8\right.$ years $)$ which smooths the effect of extinction crisis.

Due to its coarseness, the model shows only schematically the relative numerosity basal trends over time of the various taxonomic ranks, with respect to families.

The scope of the model was not to reflect the fluctuations, perhaps mainly stochastic, linked to the crises of numerosity, particularly during the phases of the "large extinctions", especially evident at family rank; on the other hand, there is a shortcoming in the model: it, by definition, cannot show the variation in the growing rate of the families, considered as stable over time.

Nevertheless, the model seems to be quite robust: the obtained trends show very few variations even if the analysed values of the taxonomic ranks do vary around an o. o. m. (order of magnitude).

The model, when applied to palaeontological or genetical data, shows quite similar results even vs. the observed patterns of the bulk of two main groups of various modellized taxonomic ranks (macrotaxa and orders v.s genera and species) over time.

It seems that the hypothetic prevalence of the assortative or the divisive evolutionary mechanism can be sufficient to explain (even if not at all to prove!) the differing basal trends in time of the larger v.s smaller taxonomic ranks.

Finally in the model, the start of Phanerozoic (" 0 " time in the analysis and " $1+0$ " in some graphs, for computing purposes) seems to be analogue, for large taxa, to a "veil line", hiding a previous phase of great phyletic diversification.

\section{Is the sampling reliable or is it mere artefact?}

An important objection to the palaeontological record analyses is linked to the theoretically predictable pattern of the curves "groups/individuals". 
These curves would predict, for the groups, a nearly logarithmic growth up to an upper limit (the real numerosity) positively related to the sample size increases. Indeed, it would be expectable that the sample sizes increase regularly and significantly with time from the geological ages to the present.

This eventual bias would at best explain in part the earliest phase of the macro-taxa curve with time, but certainly not the final phase.

Moreover, the rapid exponential growth of the final phase of the micro-taxa curve (sometime, even towards a kind of saturation of a real ecosystem space; see Machac et al., 2013) is clearly against the above-mentioned predictions, which would be necessarily linked to functions of logarithmic (and not exponential) type.

In general, the high fit of the trends over time with a third degree positive polynomial model seems to be quite different to the logistic one, theoretically expected in such a context.

In addition, it does not seem that the importance and completeness of the palaeontological sampling increased with time in the above-mentioned way (Signor, 1985). On the contrary, there are remarkable oscillations and unpredictable decreases even in recent periods because some taxa are unlikely to fossilize especially under some environmental conditions (Signor, 1985; Gould, 2002).

Thus, the observed patterns cannot be explained by classical "groups/individuals" models.

Did the observed patterns derive from the evolutive interaction between inter-taxa assortative potentiality and, conversely, subsequent isolation needs for adaptations to reproductive isolation?

Assortative evolution is often considered as exceptionally rare in the present time (however, see Gontier, 2015, without neglecting the hypothesis as brilliant as extreme, between the metaphorical and the paradigmatic, by McInerney et al., 2011) and, possibly, long before the starting of the Phanerozoic (Gould, 2002).

Some doubts about its frequency of occurrence in past times are still not solved, however, some indications have been collected. These can be summarized as follows:

(1) the number of known cases is regularly increasing (Bohm et al., 1997; Chalfie, 1998; Tyler et

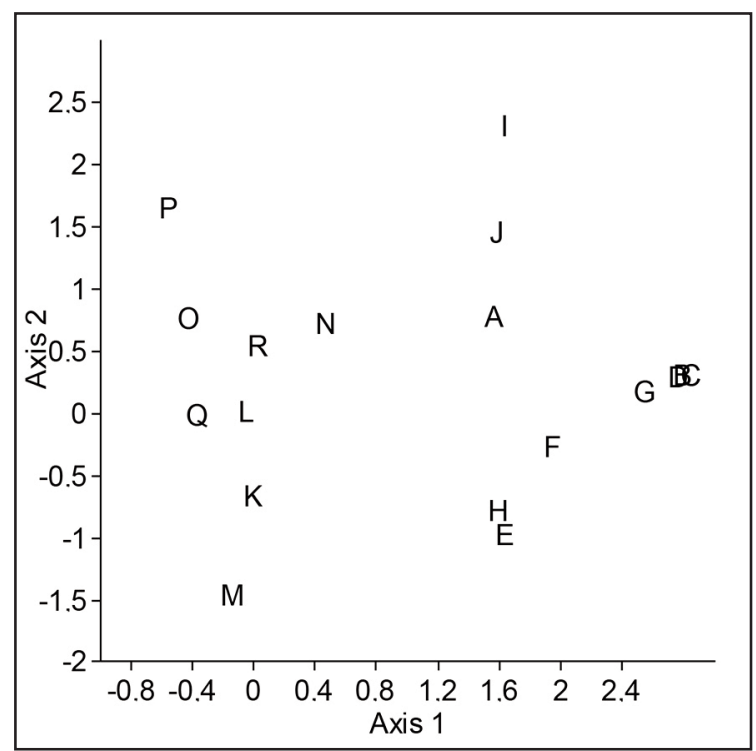

Figure 22. Detrended Correspondence analysis (B, C, and $\mathrm{D}$ are overprinted). A: Time; B: species (model P; 20); C: species (model P; 100); D: species (model G; ); E: species (observed); F: genera (model P; 4); G: genera (model P; 10); $\mathrm{H}$ : genera (model G); I: genera (observed); J: families (observed); K: orders (model P; 0,2); L: orders (model P; 0,1); $\mathrm{M}$ : orders (G); N: orders (observed); O: macrotaxa (model P; 0,04); P: macrotaxa (model P; 0,01); Q: macrotaxa $(\mathrm{G})$; $\mathrm{R}$ : macrotaxa (observed). Axis $1=87 \%$ of total.

al., 2006; Gould et al., 2008; Archibald, 2009; Moustafa et al., 2009);

(2) in various taxa, there is still a permanence of karyotypes with high $\mathrm{N}$ despite a diffused tendency to Robertsonian fusions (see Wurster \& Benirschke, 1967; Morescalchi, 1970; Capanna, 1975);

(3) the occurrence of cases of genetic homologies of structures in very distant clades; these cases are difficult to explain under purely cladogenetic or anagenetic keys of interpretation (Gould, 2002);

(4) the likely prevalence into the genome evolution of an increasing diversification rather than a reductive diversification (Omodeo, 2010).

There have also been some indications of the likely gradual and increasing role played by the inter-taxa isolation over time:

(i) the multiplicity of meiosis models, even within single macro-taxa, suggests that a long time 
distance has passed between the emergence of the clades and the fulfilment of each model;

(ii) the great number of inter-taxa reproductive isolation mechanisms, which appeared well after the separation of many large clades;

(iii) the apparently increasing, during the evolution time, of the organic (tegument, digestive - see, e. g., Doolittle, 1998 - immunitary, etc.) barriers against infections, parasitosis, etc.

\section{The general hypothetical scenario: a work- ing hypothesis}

Woese $(2002,2004)$ suggests phases of genetic sharing among organisms, before the splitting of the major evolutionary clades, as Bacteria v.s Archaea and Archaea v.s Eucaria, in connection with some "Darwinian thresholds" (i.e., the time limit after

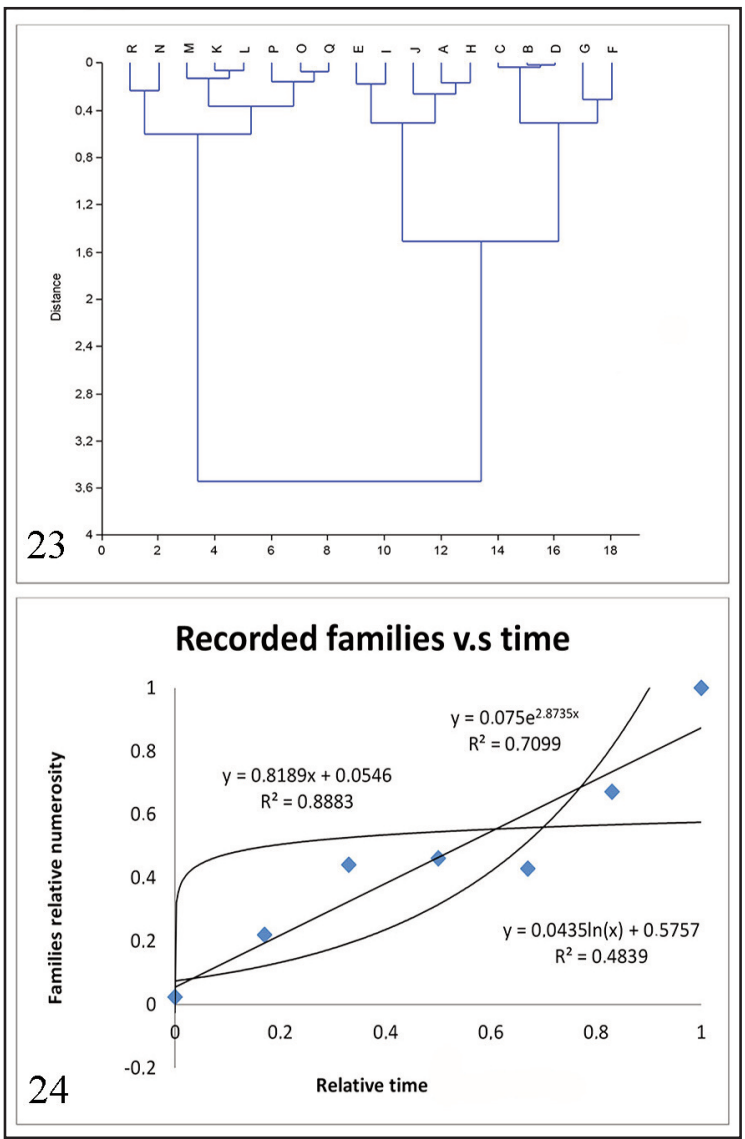

Figure 23. Cluster analysis (Ward). A to R: see above. Figure 24. Recorded Families relative to Max, in time (data from Benton, 2001) which the "modern" or "Darwinian" species do arise); their increase should be linked to divisive (reproductive isolation, competition etc.) factors.

The present analyses support such hypothesis and suggest that the following macroscopic effects of such an assortative phase may justify the trend of larger taxa, up to the early Phanerozoic. According to the model, a kind of "Darwinian threshold" can be connected with the ever growing overcome, in o. o. m. [orders of magnitude], of the species number over that of older clades.

It is likely that the earliest biocoenotic systems were regulated essentially by biochemical and macro-molecular relationships rather than by morphological relationships, as it has surely started to occur in later phases (Gould, 2002; Omodeo, 2010). Hence, based also on the patterns presented in this study (including the sense of "veil line" suggested, in the model, by the Proterozoic-Phanerozoic boundary), it seems possible to confirm that the roots of the Cambrian explosion should be retrodated by far, as the identification of the Cambrian explosion by palaeontological records is inevitably linked to the observation of macro-morphological differences among taxa.

Even genetic data seem in agreement with the above hypothesis: according to figure 2 in Hedges and Kumar (2009), up to about 600 Ma BP estimated genetic divergence did anticipate by hundreds of million of years the palaeontological phenetic one; by this period, both divergences tend gradually to synchronize.

It seems that genetic divergence, in a first (assortative?) phase had preceded and prepared the emerging of more advanced metabionts with complex development (sensu Gould, 2002).

In a second phase, due to the ever growing complexification of adaptations and decreasing probability of an evolutionary advantage of their assortments, possibly the isolation systems among new taxa have become more and more suitable and useful, perhaps also due to a growing "evo-devo" rigidity (Valentine, 1995, 2004; Erwin, 2007).

In this phase, the bulk of genetic divergence could became subsequent to the above phenomenon.

Thus, it is possible that, once overpassed the almost generalized metaclade phase among the early organisms (Penny \& Poole, 1999; Gogarten, 2000; Woese, 2004), the potential conditions for the in- 
creases in richness of living organisms may have started in a more gradual way and perhaps even before the more evident Phanerozoic explosion.

In the hypothesis of a more ancient and continuous presence of "phanerobionts" in the seas, and in an early phase with environmental niches not yet saturated, there was a prevalence in the living organisms of the assortative evolution innovations, with the origin of nearly all the phyla and of a great part of the classes, in a more biocoenotic than "chemical" context (see Penny \& Poole, 1999).

The potentials for the assortative evolution innovations tended to decrease with time in relation to a decreasing probability of qualitatively new combinations.

Later on, in the evolution time, the various adaptations tended to be increasingly refined and specialized, with the risk of altering these delicate and specialized adaptations via assortative evolution became higher than the potential advantages.

Hence, the inter-taxa isolation mechanisms (especially, but not only, the reproductive ones) became prevalent, and the evolution-by-division reached the highest impact on the taxonomic diversification of the biosphere.

Overall, also in light of Woese (2002) results, the present working hypothesis is that there would have been a passage from a phase with global opportunities of structural and metabolic innovations and of their successful genetic combinations (i.e., expressed by the Precambrian and Cambrian explosions) to a phase with prevalent and increasingly rigorous safeguard of the existing adaptations against re-merging which would have been dangerous.

As an expression of a more general pattern consistent with the above-mentioned scenario, there has been also a tendency toward the continuous increment of the relative importance of the DNA control fraction during the evolutionary complexification (Abrahamson et al., 1973; Omodeo 2010).

Obviously, the trend described above was likely accelerated when the global environmental crises (such as the Permian-Triassic one) reduced substantially the numerosity of living taxa, thus creating empty niche spaces for the "new species", which exhibited the stronger and more stable adaptations. It is from these species that the evolution would have re-started, using different modes.

The increasing inter-taxa isolation was also probably enhanced by the new requirements linked to the conquest of terrestrial environment, including, e.g., the internal fecundation requirement, the trophic niche diversification, etc. So, even the new colonization of the seas by taxa returning from the freshwater or the terrestrial environment may have also performed some non-secondary role.

Thus, in conclusion, even towards the end of the Proterozoic, the evolutionary history would have had an early "more cooperative" phase (modulated by inter-taxa innovations through macro-innovation and invasion of new empty niche spaces) and, also, for example, through the Mesozoic "taxa-grinder", a successive phase dominated by competition, with micro-differentiation and safeguard of adaptations and already-conquered niche spaces (modulated by intra-taxa innovations), this latter agreeing with the classical Darwinian theories.

In theory, there should be an obvious, inverse relationship between the taxonomically-based width of the meta-clades and their number on the basis of their respective hierarchic rank.

Also, in the physical sciences, it has been observed that the width of the free spaces covered by useful innovations necessarily decreases with time passing (Kauffman, 1993).

Whereas the present scenario of palaeontological differentiation does not conflict with general physical principles, nonetheless, it does not want to explain the stochastic, oscillating patterns of the different taxa during the different evolutionary times. The results, however, seem to be in part consistent with both the classical "Neo-Darwinism" and with the "Punctuated Equilibria" theories; less, with a strictly gradualist interpretation of the relationships among taxonomic ranks, especially during the early phases of evolution.

In synthesis, the scenario of the work suggests the possibility that the taxonomic biodiversity tends to shift increasingly and inescapably towards least comprehensive and more isolated taxa, i.e. from metaclades to the modern species (Woese, 2002). If confirmed by future results, this process may be hardly reversible, at least for the evolution of metabionts.

\section{ACKNOWLEDGEMENTS}

Tanks are due to P. Omodeo (Pisa, Italy) for the in- 
sightful observations, L. Luiselli (Roma, Italy), T. Kotsakis (Roma, Italy), A. Pavesi (Roma, Italy) and many others colleagues for the friendly assistance, J. Pignatti (Roma, Italy) for the competent consulting and G. Amori (Roma, Italy), R. Castiglia (Roma, Italy), F. Cruciani (Roma, Italy), for the helpful suggestions.

\section{REFERENCES}

Abrahamson S., Bender MA., Conger AD. \& Wolff S., 1973. Uniformity of radiation - induced mutation rates among different species. Nature, 245: 460-462.

Alroy J., Aberhan M., Bottjer D.J., Foote M., Fürsich F.T., Harries P.J., Hendy A.J.W., Holland S.M., Ivany L.C., Kiessling W., Kosnik M.A., Marshall C.R., McGowan A.J., Miller A.I., Olszewski T.D., Patzkowsky M.E., Peters S.E., Villier L., Wagner P.J., Bonuso N., Borkow P.S., Brenneis B., Clapham M.E., Fall L.M., Ferguson C.A., Hanson V.L., Krug A.Z., Layou K.M., Leckey E.H., Nürnberg S., Powers C.M., Sessa J.A., Simpson C., Tomašových A. \& Visaggi C.C., 2008. Phanerozoic trends in the global diversity of marine invertebrates. Science, 321: 97-100. DOI: 10.1126/science. 1156963

Alroy J., 2010. Geographical, environmental and intrinsic biotic controls on Phanerozoic marine diversification. Palaeontology, 53: 1211-1235.

Archibald J.M., 2009. The puzzle of plastid evolution. Current Biology, 19: R81-R88. DOI: 10.1016/j. cub.2008.11.067

Bambach R.K., 1977. Species richness in marine benthic habitats through the Phanerozoic. Paleobiology, 3: 152-167.

Bateson G., 1979. Mind and nature: a necessary unity. EP Dutton, New York.

Benson R.B.J. \& Mannion P.D., 2011. Multi-variate models are essential for understanding vertebrate diversification in deep time. Biology Letters, 8: $127-$ 130. DOI: $10.1098 / \mathrm{rsbl} .2011 .0460$

Benton M.J. (Ed.), 1993. The Fossil Record 2. Chapman and Hall, London.

Benton M.J., 2001. Biodiversity on land and in the sea. Geological Journal, 36: 211-230.

Benton M.J. \& Emerson B.C., 2007. How did life become so diverse? The dynamics of diversification according to the fossil record and molecular phylogenetics. Palaeontology, 50: 23-40.

Bohm H., Brinkmann V., Drab M., Henske A. \& Kurzchalia TV., 1997. Mammalian homologues of $C$. elegans PAR-1 are asymmetrically localized in epithelial cells and may influence their polarity. Current Biology, 7: 603-606.
Bush A.M. \& Bambach R.K., 2004. Did alpha diversity Increase during the Phanerozoic? Lifting veils of taphonomic, latitudinal and environmental biases. Geological Journal, 112: 625-642.

Butterfield N.J., 2007. Macroevolution and macroecology through deep time. Palaeontology, 50, 41-55.

Capanna E., 1975. Dati citotassonomici ed evoluzione dei vertebrati. Accademia dei Lincei, Centro Linceo Interdisciplinare, 7: 85-119.

Chalfie M., 1998. Genome sequencing - The worm revealed. Nature, 396: 620-621.

Contoli Amante L., 2007. Verso una teoria della biodiversità. Le Scienze naturali nella Scuola, 16 (32/3): 37-42.

Contoli Amante L. \& Luiselli L., 2015. Contributions to a Biodiversity Theory: the Importance of Formal Rigour. Web Ecology, 15: 33-37.

Contoli L. \& Pignatti J., 2011. Phanerozoic biodiversity, macrotaxa and families. Journal of Mediterranean Earth Sciences, 3: 73-80.

Dagan T. \& Martin W., 2009. Seeing green and red in diatom genomes. Science, 324: 1651-1652. DOI: 10. 1126/science. 1175765

Dmitriev V.Y., 2011. Evolution of Biodiversity: Hyperbola or Exponent? Paleontological Journal, 45: 705708.

Doolittle W.F., 1998. You are what You eat. Trends in Genetics, 14: 307-311.

Doolittle W.F., 2000. Uprooting the tree of life. Scientific American, 282: 72-77.

Dubey S. \& Shine R., 2010. Geographic variation in the age of temperate-zone reptile and amphibian species: Southern Hemisphere species are older. Biology Letters, 7: 96-97. DOI: 10.1098/rsb1.2010.0557

Duchène D.A., Hua X. \& Bromham L., 2017. Phylogenetic estimates of diversification rate are affected by molecular rate variation. Journal of Evolutionary Biology, 30: 1884-1897.

Eldredge N., 2015. Eternal ephemera. Adaptation and the origin of species from the nineteenth century through punctuated equilibria and beyond. Columbia University Press, New York.

Erwin D.H., 2007. Disparity: morphological pattern and developmental context. Palaeontology 50: 57-73. DOI: $10.1111 / \mathrm{j} .1475-4983.2006 .00614 . x$

Ezard T.H.G., Pearson P.N., Aze T. \& Purvis A., 2011. The meaning of birth and death (in macroevolutionary birth-death models). Biology Letters, DOI: 10.1098/rsbl.2011.0699

Farquhar J., 2009. Atmospheric Evolution, Earth. In: Gornitz V., Encyclopedia of Paleoclimates and Ancient Environments. Springer, 61-65.

Foote M., 2010. The Geological History of Biodiversity. In: Bell M.A., Futuyma D.J., Eanes W.F. \& Levinton J.S., Evolution since Darwin: the first 150 years. Oxford University Press, 479-510. 
Ganis P., 1991. La diversità specifica nelle comunità ecologiche: concetti, metodi e programmi di calcolo. GEAD - EQ n. 10 Dipartimento di Biologia Univeristà di Trieste, CETAP 100.

Gogarten P., 2000. Horizontal gene transfer: a new paradigm for biology. Esalen Center for Trend and Research Conference.

Goldenfeld N. \& Woese C., 2007. Connections Biology's next revolution. Nature, 445: 369.

Gompel N., Prud'homme B., Wittkopp PJ., Kassner VA. \& Carrol SB., 2005. Chance caught on the wing: cisregulatory evolution and the origin of pigment patterns in Drosophila. Nature, 433: 481-487.

Gontier N., 2015. Reticulate Evolution Everywhere. In: Gontier N., Reticulate Evolution. Interdisciplinary Evolution Research 3, Springer, $\mathrm{CH}$.

Gould S.B., Waller R.F. \& McFadden G.I., 2008. Plastid evolution. Annual Review of Plant Biology, 59: 491517. DOI: 10.1146/annurev.arplant.59.032607.0929 15

Gould S.J., 1989. Wonderful Life: The Burgess Shale and the nature of history. WW Norton and Company, New York and London.

Gould S.J., 2002. The Structure of Evolutionary Theory. The Belknap Press of Harvard U P, Cambridge (Mass.) and London.

Gould S.J., Raup D.M., Sepkoski J.J. Jr., Schopf T.J.M. \& Simberloff D.S., 1977. The shape of evolution: A comparison of real and random clades. Paleobiology, 3: $23-40$.

Hedges S.B. \& Kumar S. (Eds.), 2009. The Timetree of Life. Oxford U P, Oxford and New York.

Hoffman A., 1985. Biotic diversification in the Phanerozoic: diversity independence. Palaeontology, 28: 387-391.

Holland S.M. \& Sclafani J.A., 2015. Phanerozoic diversity and neutral theory. Paleobiology, 41: 369-376. DOI: $10.1017 /$ pab.2015.10

Jackson J.B.C. \& Johnson K.G., 2001. Measuring past biodiversity. Science, 293: 2401-2404.

Karhu J.A., 2012. Evolution of Earth"s Atmosphere. In: Haapala I., 2012. From the Earth"s Core to Outer Space, Springer, 187-198.

Kauffman S.A., 1993. The origins of Order: Self - organization and selection in Evolution. Oxford U P, Oxford.

Kleine T., Maier U.G. \& Leister D., 2009. DNA transfer from organelles to the nucleus: The idiosyncratic genetics of endosymbiosis. Annual Review of Plant Biology, 60: 125-138.

Landman O.E., 1991. The inheritance of acquired characteristics. Annual Review of Genetics, 25: 1-20.

Lane A. \& Benton M.J., 2003. Taxonomic rank as a determinant of the shape of the Phanerozoic marine biodiversity curve. American Naturalist, 162: 265-276. DOI: $10.1086 / 377188$
Liu Y.S., 2011. Inheritance of acquired characters in animals: A historical overview, further evidence and mechanistic explanations. Italian Journal of Zoology, 78: 410-417. DOI: 10.1080/11250003.2011.562554

Lloyd G.T., 2011. A refined modelling approach to asses the influence of sampling on palaeobiodiversity curves: new support for declining Cretaceous dinosaur richness. Biology Letters, 8: 123-126. DOI: 10.1098/rsbl.2011.0210

Machac A., Storch D. \& Wiens J.J., 2013. Ecological causes of decelerating diversification in carnivoran mammals. Evolution, 67: 2423-2433.

Markov A.V. \& Korotayev A.V., 2007. Phanerozoic marine biodiversity follows a hyperbolic trend. Palaeoworld, 16: 311-318. DOI: 10.1016/j.palwor.2007. 01.002

Marshall C.R., 2010. Marine Biodiversity Dynamics over Deep Time. Science, 329: 1156.

Mayr E., 1982. The growth of biological thought: diversity, evolution, and inheritance. The Belknap Press of Harvard U P, Cambridge (Mass.) and London.

Mc Gowan A.J. \& Smith A.B., 2008. Are global Phanerozoic marine diversity curves truly global? A study of the relationship between regional rock records and global Phanerozoic marine diversity. Paleobiology, 34: 80-103. DOI: 10.1666/07019.1

McInerney J.O., Pisani D., Bapteste E. \& O’Connell M. J., 2011. The public goods hypothesis for the evolution of life on Earth. Biology Direct, 6: 41. DOI: 10.1186/1745-6150-6-41.

Michaux J., Reyes A. \& Catzeflis F., 2001. Evolutionary history of the most speciose mammals: Molecular phylogeny of muroid rodents. Molecular Biology and Evolution, 18: 2017-2031.

Morescalchi A., 1970. Karyology and vertebrate phylogeny. Bollettino Zoologia, 37: 1-28.

Moustafa A., Beszteri B., Maier U.G., Bowler C., Valentin K. \& Bhattacharya D., 2009. Genomic footprints of a cryptic plastid endosymbiosis in diatoms. Science, 324: 1724-1726.

Murphy W.J., Eizirik E., Johnson W.E., Ya Ping Zhang., Ryder O.A. \& O’Brien S.J., 2012. Molecular phylogenetics and the origins of placental mammals. Nature, 409: 614-618.

Novacek M.J., 1992. Mammalian phylogeny: Shaking the tree. Nature, 356: 121-125.

Oakley T.H., 2017. Furcation and fusion: The phylogenetics of evolutionary novelty. Developmental Biology, 431: 69-76. DOI: 10.1016/j.ydbio.2017.09.015

Ohno S., 1970. Evolution by gene duplication. Springer, Berlin.

Omodeo P., 1985. Progressive evolution and increase of genetic information. In: Pesce - Delfino V. 1985. International Symposium Biology and Evolution, 2338 . 
Omodeo P., 2010. Evoluzione della cellula. ETS, Pisa.

Penny D. \& Poole A., 1999. The nature of the Last Universal Common Ancestor. Current Opinion in Genetics \& Development, 9: 672-677.

Raup D.M., 1976a. Species diversity in the Phanerozoic: a tabulation. Paleobiology, 2: 279-288.

Raup D.M., 1976b. Species diversity in the Phanerozoic: an interpretation. Paleobiology, 2: 289-297.

Rensch B., 1959. Evolution above the species rank. Methuen and Co, London.

Rogozin I.B., Basu M.K., Csürös M. \& Koonin E.V., 2009. Analysis of rare genomic changes does not support the unikont-bikont phylogeny and suggests cyanobacterial symbiosis as the point of primary radiation of eukaryotes. Genome Biology and Evolution, 25: 99-113. DOI: 10.1093/gbe/evp011

Ruban D.A., 2010. Do new reconstructions clarify the relationships between the Phanerozoic diversity dynamics of marine invertebrates and long-term eustatic trends? Annales de Paléontologie, 96: 51-59.

Sánchez-Puerta M.V. \& Delwiche C.F., 2008. A hypothesis for plastid evolution in chromalveolates (minireview). Journal of Phycology, 44: 1097-1107.

Schopf T.J.M., 1979. The role of biogeographic provinces in regulating marine faunal diversity through geologic time. In: Gray J. \& Boucout A.J. (Eds.), Historical biogeography, plate tectonics, and the changing environment, Oregon St U P, Corvallis, 449-457.

Sepkoski J.J. Jr., 1978. A kinetic model of Phanerozoic taxonomic diversity. I: Analysis of marine orders. Paleobiology, 4: 223-251.

Sepkoski J.J. Jr., 1979. A kinetic model of Phanerozoic taxonomic diversity. II: Early Phanerozoic families and multiple equilibria. Paleobiology 5: 222-251.

Sepkoski J.J. Jr., 2002. A compendium of fossil marine animal genera. Bulletins of American Paleontology, 363: $1-560$.

Signor P.W., 1978. Species richness in the Phanerozoic: an investigation on sampling effects. Paleobiology, 4: 394-406.

Signor P.W., 1982. Species richness in the Phanerozoic: compensating for sampling bias. Geology, 10: 625628.

Signor P.W., 1985. Real and apparent trends in species richness through time. In: Valentine JW., Phanerozoic diversity patterns. Princeton UP, Princeton, 129-150.

Smith A.B., 2001. Large-scale heterogeneity of the fossil record: implications for Phanerozoic biodiversity studies. Philosophical Transactions of the Royal Society of London. Series B, 356: 351-367.

Smith A.B., 2007. Marine diversity through the Phanerozoic: problems and prospects. Journal of the Geological Society, 164: 731-745. DOI: 10.1144/0016/ 76492006-184
Stanley S.M., 1979. Macroevolution: Pattern and Process. WH Freeman, San Francisco.

Taylor F.J.R., 1979. Symbionticism revisited: a discussion of the evolutionary impact of intracellular symbioses. Proceedings of the Royal Society of London B, 204: 267-286.

Tyler B.M., Tripathy S., Zhang X., Dehal P., Jiang R.H.Y., Aerts A., Arredondo F.D., Baxter L., Bensasson D., Beynon J.L., Chapman J., Damasceno C.M.B., Dorrance A.E., Dou D., Dickerman A.W., Dubchak I.L, Garbelotto M., Gijzen M., Gordon S.G., Govers F., Grunwald N.J., Huang W., Ivors K.L., Jones R.W., Kamoun S., Krampis K., Lamour K.H., Lee M.K., McDonald W.H., Medina M., Meijer H.J.G., Nordberg E.K., Maclean D.J., Ospina-Giraldo M.D., Morris P.F., Phuntumart V., Putnam N.H., Rash S., Rose J.K.C., Sakihama Y., Salamov A.A., Savidor A., Scheuring C.F., Smith B.M., Sobral B.W.S., Terry A., Torto-Alalibo T.A., Win J., Xu Z., Zhang H., Grigoriev I.V., Rokhsar D.S. \& Boore J.L., 2006. Phytophthora genome sequences uncover evolutionary origins and mechanisms of pathogenesis. Science, 313: 1261-1266. DOI: 10.1126/science. 1128796

Valentine J.W., 1970. How many marine invertebrate fossil species? A new approximation. Journal of Paleontological, 44: 410-415.

Valentine J.W., 1995. Why no new phyla after the Cambrian? Genome and ecospace hypotheses revisited. Palaios, 10: 190-194. DOI:10.2307/3515182

Valentine J.W., 2004. On the origin of phyla. Chicago, IL: University of Chicago Press.

Valentine J.W., Foin T.C. \& Peart D., 1978. A provincial model of Phanerozoic marine diversity. Paleobiology, 4: 55-66.

Valentine J.W. \& Moores E.M., 1970. Plate - tectonic regulation of faunal diversity and sea rank: a model. Nature, 228: 657-659.

Warnock R.C.M., Yang Ziheng, Donoghue P.C.J., 2011. Exploring uncertainty in the calibration of the molecular clock. Biology Letters, 8: 156-159.

Williamson D., 2003. The origins of larvae. 2nd revised ed. Springer, Berlin.

Wise K.P. \& Schopf T.J.M., 1981. Was marine faunal diversity in the Pleistocene affected by changes in sea rank? Paleobiology, 7: 394-399.

Woese C.R., 2002. On the evolution of the cells. Proceedings of the National Academy of Sciences, 99: 87428747. DOI: $10.1073 /$ pnas.132266999

Woese C.R., 2004. A new biology for a new century. Microbiology and Molecular Biology Reviews, 68: 173-186. DOI: 10.1128/MMBR.68.2.173-186.2004

Wurster-Hill D.H. \& Benirschke K., 1967. The chromosomes of twenty - three species of the Cervoidea and Bovoidea. Mammals Chrome Newsl, 8: 226-229. 